\title{
Informal Caregiving for a Person with Dementia: The Role of Social and Psychological Capital
}

\author{
Anne Marie McMahon and Tony Cassidy* \\ Ulster University, UK
}

Submission: September 24, 2018; Published: January 03, 2019

*Corresponding author: Tony Cassidy, University Cromore Road, Northern Ireland, UK.

\begin{abstract}
Background: The demands associated with informal caregiving for a person with dementia have been shown to lead to high levels of stress in caregivers. This not only has serious consequences for caregiver health but also reduces their effectiveness as a caregiver. The aim of this study was to explore these issues and to investigate the potential mediation impact of social and psychological capital.
\end{abstract}

Method: A cross-sectional survey using questionnaire date collection was completed by 326 family caregivers for a person with dementia, recruited through support groups and day-care centres.

Results: A cross-sectional survey using questionnaire date collection was completed by 326 family caregivers for a person with dementia, recruited through support groups and day-care centres.

Conclusion: A cross-sectional survey using questionnaire date collection was completed by 326 family caregivers for a person with dementia, recruited through support groups and day-care centres.

Keywords: Caregiver; Psychological capital, Social support; Unmet needs; Psychological well-being

\section{Introduction}

Dementia is a syndrome which occurs due to impairment in the cortical and/or sub-cortical region of the brain which may be due to different factors and diseases, of which Alzheimer's disease is the most common [1]. The syndrome is characterised by progressive deterioration in mental functioning which affects memory and other cognitive skills and can result in gradual loss of the ability to function independently. This loss of mental function is often accompanied by a reduction in emotional control, social behaviours and motivation [2]. The occurrence of dementia tends to increase with age which means that as life expectancy increases and the global population ages, dementia incidence would be expected to increase also [3]. The Alzheimer Society of Ireland estimate that there are 55,000 people living with dementia in Ireland at present and Pierce et al. [3] have estimated that this could rise to as many as 70,000 in 2021 or 147,000 in 2041.

Over the past forty years there has been a growing recognition in healthcare that adults with dependency needs are best cared for in the home environment [4]. Up to 12 per cent of UK adults are currently estimated to be involved in informal caring and it is estimated that this will double in the next few decades. One of its key objectives of dementia care is that it should facilitate individuals to remain in their own home for as long as possible [3]. Given the depletion of health services family members tend to be the main support for people with dementia who reside in their own homes and many of the required services are provided by the voluntary and informal sector [5] Schulz \& Martire [6] have suggested that caregiving for a person with dementia results in exposure to chronic stress which occurs due to the cognitive impairment and the need for physical assistance, as well as behaviour problems and the need for constant supervision. As a result, family caregivers have been reported to suffer emotional distress and upset which may make them more vulnerable to disease due to altered immune function and other physiological consequences of stress and also due to changes in their own cognition and behaviour [7].

The ability of a caregiver to provide care for a person with dementia is reduced by the level of burden or stress which he/she experiences [8]. Caregiver stress is a predictor of nursing home placement of persons with dementia $[9,10]$ although this effect is difficult to verify due to lack of consistency in the measures used to quantify caregiver burden or strain in different studies [11]. It is thought that training and education of caregivers about dementia and provision of suitable support and respite in the community could reduce stress for both carer and care recipient, thereby increasing the likelihood that the person with dementia can continue to be cared for at home [12]. Caregivers who perceive unmet needs for support, respite or the opportunity to look after their own health and well-being experience more subjective and 
objective burden [13-15] however some studies have shown caregiver reluctance to avail of provided services and supports [16]. As the needs of caregivers and PwD change over time as the dementia progresses, it is important that service and support needs are reassessed regularly to ensure that they are adequate to meet the current need [17].

Personal resources of the caregiver may also affect caregiver well-being through their influence on the ability to adapt to stress and to the demands of the caregiving role [18]. Caregivers' perception of the social support available to them has been shown to be associated with well-being [19] however the demands of the caregiving role often result in reduction of caregiver's social networks and support over time [20]. The perception of having social support is also important for building the resilience necessary to adapt to the demands of the caregiving role [21].

A review by Harmell, Chattillion, Roepke \& Mausbach [22] found that higher levels of self-efficacy and personal mastery, as well as the use of positive coping strategies were protective of the effects of caregiver stress on well-being. Self-efficacy in caregivers has also been reported to moderate the relationship between occurrence of challenging behaviours and caregiver distress $[23,24]$. Psychological resilience, the ability to adapt in response to adversity, threat or stress, has been posited as important to enable caregivers to adapt and adjust to the circumstances and stresses of their caregiving role and has been shown to predict depressive symptoms in spousal caregivers of persons with Alzheimer disease [25]. Both self-efficacies to fulfil the role of caregiver and manage behaviour problems and adequate social support have been reported as essential features of resilience in caregivers [26]. Optimism and hope are two further resources which have been shown to influence health and well-being [27]. Optimism, a cognitive construct which influences a person's expectations of the outcomes they will experience in life and has a motivational element to it has both state and trait-like elements [28]. Hope is also considered to be a motivational state which influences a person's sense of agency in relation to achieving goals and in relation to finding the means to achieve those goals [29]. Valle, [30] found that hope seemed to act as a moderator between stressful life events and well-being in adolescents. The construct of psychological capital [31] as accumulated evidence as a personal resource which enables individuals to cope with stress [32,33]. Psychological capital is a composite of self-efficacy, optimism, resilience and hope.

The aim of the current study was to explore the role of social support and psychological capital in relation to the experience, stress and wellbeing of care givers of a person with dementia.

\section{Method}

\section{Participants and procedure}

Participants were 326 (258 females and 68 males) informal primary family dementia caregivers. They were aged between 45 and 88 years of age with $47=36-45$ years, $204=46-55$ years, $39=56-65$ years, $23=66-75$ years, and $13=76-88$ years. Of the caregivers, 196 were married, 87 were divorced/separated, 15 were widowed and 28 were living with a partner. In terms of education, 29 had not attended beyond primary school level, 146 had finished at secondary level and 151 had attended third level college. 153 of caregivers did not work outside the home, 61 worked part-time and 112 worked full-time. The length of time since diagnosis ranged from 6 to 180 months (15 years) with the mean being 67.29 (36.62). Participants were recruited through caregiver support groups, day care centres, online support groups and through snowball sampling. The study was approved by the School of Psychology Filter Committee, Ulster University and all participants gave informed consent.

\section{Measures}

Demographic details were collected on age and sex (both carer and care recipient), duration of caring, number of hours per week caring, and whether the needs of the care recipient were being met by health care services. The following measures were used.

The Dependence Scale [34,35] was used to estimate the level of care required by the care recipient. This scale was developed as a means of assessing care needs arising due to impairments in cognition, function and behaviour. It has been shown to have adequate construct validity and internal consistency (Cronbach's $\alpha \geq$.66) [36]. Caregivers are asked questions which explore how dependent the care recipient is on assistance from others in day to day activities. Cronbach alpha in this data was .73.

The Psychological Capital Questionnaire [31] was used to measure the four factors of resilience $(\alpha=.87)$, self-efficacy ( $\alpha=$ .77), hope $(\alpha=.78)$ and optimism $(\alpha=.82)$.

The Perceived Stress (10 item) scale [37] was used to assess carer's perceived stress. This is a ten-item self-report scale which assesses how uncontrollable, unpredictable or overloaded the participants feel their lives are. This scale has been shown to have adequate internal consistency (Cronbach's $\alpha=.85$ ) and test-retest reliability.

The Multidimensional Scale of Perceived Social Support [38] was used to assess caregivers' perception of the social support available to them. This twelve-item measure assesses the perceived support available from friends, family and a significant other. It has been shown to have good internal consistency ( $\alpha$ $=.85)$.

The 7-item Short Warwick-Edinburgh Mental Well-Being Scale (SWEMWBS) [39] was used to measure psychological well-being of the caregiver. The SWEMWBS is a measure of mental well-being in general populations. It covers both subjective well-being and psychological functioning. It has been shown to have good content validity, internal consistency (Cronbach's $\alpha=.90$ ).

\section{Results}

The mean score for mental well-being in the study sample was $21.68(\mathrm{Sd}=5.44)$ which falls below the mean population norm (23.62 +/-3.9) from Health Survey for England data 2011. One sample t-test shows that this difference is significant ( $t$ (325) 
$=6.435, \mathrm{p}<.001)$. The mean score on perceived stress $(22.2+/-$ 6.53) was above the population mean of 13.02. Again, a onesample t-test shows this to be statistically significant ( $\mathrm{t}$ (325) $=22.79$, p<.001).

To assess how the relationship between caregiving experience, social support, psychological capital and caregiver stress, hierarchical multiple regression (HMRA) was performed with caregiver stress as the dependent variable. On step one age and sex of both care giver and care recipient were entered and accounted for $3.8 \%$ of the variance in stress. On step two care duration, number of hours caring each week, and level of dependence on carer were entered and added $11.7 \%$ to variance explained. On step three perception of whether services were meeting the needs of the person with dementia was added and provided an additional $2.4 \%$ to variance explained. On the final step social support and psychological capital were added accounting for a further $38.8 \%$ of variance (Table 1 ).

Table 1: The predictors of perceived stress from hierarchical multiple regression.

\begin{tabular}{|c|c|c|c|c|c|}
\hline & B & SE. B & b & t & $\mathbf{P}$ \\
\hline \multicolumn{6}{|c|}{ Step 1: $\mathrm{R}^{2}=.038, \mathrm{~F}(4,321)=3.153, \mathrm{p}<.015$} \\
\hline Care recipient Sex & -0.77 & 0.745 & -0.059 & -1.034 & 0.302 \\
\hline Care recipient Age & 0.174 & 0.427 & 0.023 & 0.408 & 0.683 \\
\hline Carer Sex & -0.456 & 0.861 & -0.031 & -0.529 & 0.597 \\
\hline Carer Age & 0.794 & 0.286 & 0.164 & 2.773 & 0.006 \\
\hline \multicolumn{6}{|c|}{ Step 2: $\mathrm{DR}^{2}=.117, \mathrm{~F}(3,318)=14.697, \mathrm{p}=.001$} \\
\hline Care recipient Sex & -1.004 & 0.732 & -0.077 & -1.372 & 0.171 \\
\hline Care recipient Age & -0.544 & 0.477 & -0.07 & -1.141 & 0.255 \\
\hline Carer Sex & 0.996 & 0.866 & 0.067 & 1.15 & 0.251 \\
\hline Carer Age & 1.521 & 0.298 & 0.315 & 5.106 & 0 \\
\hline Care duration & -0.028 & 0.01 & -0.173 & -2.789 & 0.006 \\
\hline Weekly care (hrs) & -0.049 & 0.009 & -0.373 & -5.611 & 0 \\
\hline Dependence on Carer & 0.561 & 0.169 & 0.208 & 3.319 & 0.001 \\
\hline \multicolumn{6}{|c|}{ Step 3: $\mathrm{DR}^{2}=.024, \mathrm{~F}(1,317)=9.241, \mathrm{p}=.003$} \\
\hline Care recipient Sex & -1.282 & 0.728 & -0.098 & -1.761 & 0.079 \\
\hline Care recipient Age & -0.626 & 0.471 & -0.081 & -1.328 & 0.185 \\
\hline Carer Sex & 0.549 & 0.868 & 0.037 & 0.632 & 0.528 \\
\hline Carer Age & 1.389 & 0.297 & 0.287 & 4.668 & 0 \\
\hline Care duration & -0.026 & 0.01 & -0.16 & -2.604 & 0.01 \\
\hline Weekly care (hrs) & -0.05 & 0.009 & -0.384 & -5.849 & 0 \\
\hline Dependence on Carer & 0.671 & 0.171 & 0.249 & 3.928 & 0 \\
\hline Needs met & -2.268 & 0.746 & -0.164 & -3.04 & 0.003 \\
\hline \multicolumn{6}{|c|}{ Step 4: $\mathrm{DR}^{2}=.388, \mathrm{~F}(2,315)=141.10, \mathrm{p}<.001$} \\
\hline Care recipient Sex & -0.035 & 0.537 & -0.003 & -0.064 & 0.949 \\
\hline Care recipient Age & -2.063 & 0.357 & -0.267 & -5.783 & 0 \\
\hline Carer Sex & 2.264 & 0.651 & 0.152 & 3.48 & 0.001 \\
\hline Carer Age & 0.552 & 0.23 & 0.114 & 2.4 & 0.017 \\
\hline Care duration & -0.011 & 0.007 & -0.069 & -1.526 & 0.128 \\
\hline Weekly care (hrs) & -0.045 & 0.006 & -0.344 & -7.168 & 0 \\
\hline Dependence on Carer & 0.65 & 0.124 & 0.241 & 5.223 & 0 \\
\hline Needs met & -0.835 & 0.551 & -0.06 & -1.514 & 0.131 \\
\hline Social support & -0.059 & 0.018 & -0.159 & -3.295 & 0.001 \\
\hline Psychological capital & -0.421 & 0.035 & -0.6 & -12.12 & 0 \\
\hline
\end{tabular}

Overall the model accounted for $55 \%$ of the variance in stress and on the final step the significant predictors of stress were, age of the care recipient $(b=-.267, p<.001)$, sex of the carer $(b=.152$, $\mathrm{p}<.001)$, age of the carer $(\mathrm{b}=.114, \mathrm{p}<.01)$, number of hours per week caring $(b=.344, p<.001)$, how dependent the care recipient was on the carer $(b=.241, p<.001)$, social support $(b=-.159$, $\mathrm{p}<.001)$, and psychological capital $(\mathrm{b}=-.600, \mathrm{p}<.001)$. The younger the care recipient, male carers, older carers, more hours of caring 
per week, and higher dependence on the carer corresponds with higher levels of stress. On the other hand, the greater the perceived support and the more reported psychological capital related to lower levels of stress. This does not mean that other variables are not important. For example, duration of caring was significant on earlier steps in the analysis but when social support and psychological capital were added it was no longer significant. Essentially social support and psychological capital moderate its effect.

Table 2: The predictors of wellbeing from hierarchical multiple regression analyses.

\begin{tabular}{|c|c|c|c|c|c|}
\hline & B & SE. B & b & t & $\mathbf{P}$ \\
\hline \multicolumn{6}{|c|}{ Step 1: $\mathrm{R}^{2}=.181, \mathrm{~F}(4,321)=17.69, \mathrm{p}<.001$} \\
\hline Care recipient Sex & 2.075 & 0.573 & 0.19 & 3.624 & 0.001 \\
\hline Care recipient Age & -1.232 & 0.329 & -0.191 & -3.749 & 0.001 \\
\hline Carer Sex & 3.255 & 0.662 & 0.263 & 4.916 & 0.001 \\
\hline Carer Age & -0.543 & 0.22 & -0.135 & -2.464 & 0.014 \\
\hline \multicolumn{6}{|c|}{ Step 2: $\mathrm{DR}^{2}=.022, \mathrm{~F}(3,318)=2.978, \mathrm{p}=.034$} \\
\hline Care recipient Sex & 2.276 & 0.592 & 0.209 & 3.844 & 0.001 \\
\hline Care recipient Age & -0.947 & 0.386 & -0.147 & -2.456 & 0.015 \\
\hline Carer Sex & 2.878 & 0.701 & 0.233 & 4.106 & 0.001 \\
\hline Carer Age & -0.756 & 0.241 & -0.188 & -3.135 & 0.002 \\
\hline Care duration & 0.006 & 0.008 & 0.043 & 0.722 & 0.471 \\
\hline Weekly care (hrs) & 0.019 & 0.007 & 0.17 & 2.64 & 0.009 \\
\hline Dependence on Carer & -0.1 & 0.137 & -0.045 & -0.732 & 0.465 \\
\hline \multicolumn{6}{|c|}{ Step 3: $\mathrm{DR}^{2}=.003, \mathrm{~F}(1,317)=1.220, \mathrm{p}=.270$} \\
\hline Care recipient Sex & 2.359 & 0.597 & 0.217 & 3.954 & 0.001 \\
\hline Care recipient Age & -0.923 & 0.386 & -0.143 & -2.39 & 0.017 \\
\hline Carer Sex & 3.011 & 0.711 & 0.243 & 4.235 & 0.001 \\
\hline Carer Age & -0.716 & 0.244 & -0.178 & -2.94 & 0.004 \\
\hline Care duration & 0.005 & 0.008 & 0.039 & 0.643 & 0.521 \\
\hline Weekly care (hrs) & 0.019 & 0.007 & 0.174 & 2.7 & 0.007 \\
\hline Dependence on Carer & -0.133 & 0.14 & -0.059 & -0.949 & 0.344 \\
\hline Needs met & 0.675 & 0.611 & 0.059 & 1.105 & 0.27 \\
\hline \multicolumn{6}{|c|}{ Step 4: $D^{2}=.481, F(2,315)=242.220, p<.001$} \\
\hline Care recipient Sex & 1.143 & 0.38 & 0.105 & 3.01 & 0.003 \\
\hline Care recipient Age & 0.502 & 0.252 & 0.078 & 1.988 & 0.048 \\
\hline Carer Sex & 1.167 & 0.46 & 0.094 & 2.534 & 0.012 \\
\hline Carer Age & -0.087 & 0.163 & -0.022 & -0.536 & 0.592 \\
\hline Care duration & -0.007 & 0.005 & -0.053 & -1.378 & 0.169 \\
\hline Weekly care (hrs) & 0.014 & 0.004 & 0.133 & 3.267 & 0.001 \\
\hline Dependence on Carer & -0.113 & 0.088 & -0.05 & -1.277 & 0.202 \\
\hline Needs met & -0.723 & 0.39 & -0.063 & -1.853 & 0.065 \\
\hline Social support & 0.095 & 0.013 & 0.311 & 7.561 & 0.001 \\
\hline Psychological capital & 0.329 & 0.025 & 0.563 & 13.384 & 0.001 \\
\hline
\end{tabular}

The HMRA was repeated with wellbeing as the dependent variable (Table 2). Overall the model accounted for $67.8 \%$ of the variance in wellbeing and on the final step the significant predictors of wellbeing were, sex of the care recipient $(b=.105$, $\mathrm{p}<.01)$, age of the care recipient $(\mathrm{b}=-.078, \mathrm{p}<.05)$, sex of the carer $(b=.94, p<.01)$, number of hours per week caring $(b=.133, p<.001)$, social support $(b=-.311, p<.001)$, and psychological capital $(b=-$
.563, p<.001). A male care recipient, younger the care recipient, and male carers, correlated with lower levels of wellbeing. On the other hand, the greater the perceived support and the more reported psychological capital related to higher levels of wellbeing. Again, other variables were significant predictors of wellbeing on earlier steps. For example, age of carer, but the effect was moderated by social support and psychological capital. 
Given the impact of social support and psychological capital the next stage in analysis was to input the separate dimensions of each as independent variables in a further HMRA (Table 3). Between them the separate dimensions of social support and psychological capital accounted for $44.5 \%$ of the variance in stress. Overall, support from significant other $(b=-.354, p<.001)$, family support $(b=-.318, p<.001)$, self-efficacy $(b=-.488, p<.001)$, optimism ( $b=-.168, p<.01)$, and resilience $(b=-.174, p<.01)$, were significantly related to stress. Participants with higher levels of stress reported less support from significant others and family, and lower levels of self-efficacy, optimism, and resilience.

Table 3: The dimensions of support and psychological capital regressed onto perceived stress.

\begin{tabular}{|c|c|c|c|c|c|}
\hline & B & SE. B & b & t & $\mathbf{P}$ \\
\hline \multicolumn{6}{|c|}{ Step 1: $\mathrm{R}^{2}=.160, \mathrm{~F}(3,322)=20.418, \mathrm{p}<.015$} \\
\hline Sig. other support & 0.096 & 0.043 & 0.121 & 2.255 & 0.025 \\
\hline Family support & -0.353 & 0.059 & -0.355 & -5.994 & 0.001 \\
\hline Friend support & -0.131 & 0.074 & -0.102 & -1.777 & 0.076 \\
\hline \multicolumn{6}{|c|}{ Step 2: $\mathrm{DR}^{2}=.297, \mathrm{~F}(4,318)=43.449, \mathrm{p}=.001$} \\
\hline Sig. other support & 0.118 & 0.04 & 0.149 & 2.966 & 0.003 \\
\hline Family support & -0.316 & 0.054 & -0.318 & -5.81 & 0.001 \\
\hline Friend support & -0.032 & 0.061 & -0.025 & -0.524 & 0.601 \\
\hline Self-efficacy & -1.174 & 0.128 & -0.488 & -9.176 & 0.001 \\
\hline Optimism & 0.368 & 0.125 & 0.168 & 2.954 & 0.003 \\
\hline Hope & -0.126 & 0.219 & -0.05 & -0.576 & 0.565 \\
\hline Resilience & -0.485 & 0.187 & -0.174 & -2.587 & 0.01 \\
\hline
\end{tabular}

Table 4: The dimensions of support and psychological capital regressed onto wellbeing.

\begin{tabular}{|c|c|c|c|c|c|}
\hline & B & SE. B & b & $\mathbf{t}$ & $\mathbf{P}$ \\
\hline \multicolumn{6}{|c|}{ Step 1: $\mathrm{R}^{2}=.378, \mathrm{~F}(3,322)=65.310, \mathrm{p}<.001$} \\
\hline Sig. other support & -0.206 & 0.031 & -0.31 & -6.744 & 0 \\
\hline Family support & 0.345 & 0.042 & 0.417 & 8.172 & 0 \\
\hline Friend support & 0.296 & 0.053 & 0.276 & 5.603 & 0 \\
\hline \multicolumn{6}{|c|}{ Step 2: $\mathrm{DR}^{2}=.139, \mathrm{~F}(4,318)=22.895, \mathrm{p}=.001$} \\
\hline Sig. other support & -0.234 & 0.031 & -0.353 & -7.463 & 0 \\
\hline Family support & 0.346 & 0.043 & 0.419 & 8.118 & 0 \\
\hline Friend support & 0.238 & 0.048 & 0.221 & 4.961 & 0 \\
\hline Self-efficacy & 0.707 & 0.101 & 0.353 & 7.031 & 0 \\
\hline Optimism & 0.029 & 0.098 & 0.016 & 0.298 & 0.766 \\
\hline Hope & -0.085 & 0.172 & -0.04 & -0.494 & 0.622 \\
\hline Resilience & 0.193 & 0.147 & 0.083 & 1.309 & 0.192 \\
\hline
\end{tabular}

HMRA was repeated with wellbeing as the dependent variable (Table 4). Between them the separate dimensions of social support and psychological capital accounted for $50.7 \%$ of the variance in wellbeing. Overall, support from significant other $(b=-.149$, $\mathrm{p}<.01)$, family support $(\mathrm{b}=-.419, \mathrm{p}<.001)$, friend support $(\mathrm{b}=-.221$, $\mathrm{p}<.001)$, and self-efficacy $(\mathrm{b}=-.353, \mathrm{p}<.001)$, were significantly related to wellbeing. Participants with higher levels of wellbeing also scored higher on support from friends, family, and significant others, and reported higher levels of self-efficacy.

\section{Discussion}

The aim of this study was to explore the relationship between caregiving for a person with dementia and the mental well- being of the informal caregiver and to see how this is influenced by their own psychological resources and social supports. Significant associations were found between caregiver wellbeing and perceived stress and the psychological capital, social support variables and satisfaction with needs met. Mean levels of perceived stress among caregivers in this study sample were significantly above population norm. This is of concern as higher stress levels have negative implications for physical health, psychological well-being and quality of life [40]. In the current study, perceived stress was negatively associated with caregiver mental well-being, psychological capital, social support and with needs met. This indicates that increasing levels in these variables would be associated with reduced stress. Hierarchical 
multiple regression indicated that care recipient needs not met was positively associated with perceived stress while this effect was reduced when perceived social support and psychological capital were added. This would appear to indicate that where the caregiver perceives that they have not received sufficient supports and services to fill the needs of the person with dementia they are more likely to suffer the consequences of stress. In this instance, social support and psychological capital appear to reduce this effect, suggesting that they could either enable the caregiver to fill the unmet need or that they enable the caregiver to adapt and cope with the fact that the perceived need has not been met.

Social support has been shown to be protective of health and to act as a buffer against psychological distress arising from stress [41-43]. Donnellan, Bennett \& Soulsby [44] explored how social support might contribute to resilience in spousal caregivers of persons with dementia. They observed a difference in benefit from social support, measured in terms of building psychosocial resources, according to the type of social support and how well the caregiver felt it matched his/her needs. Au et al. [45] found that caregiving self-efficacy partially mediated the relationship between social support and depressive symptoms in dementia family caregivers and that caregivers who experienced more social support were more confident of their ability to manage care and to obtain respite if necessary. In the current study, psychological capital also appears to mediate the relationship between care giving and perceived stress. Previous studies have demonstrated the influence of the components of psychological capital, selfefficacy, optimism, hope and resilience, on the caregiving role and Rabenu \& Yaniv [46] found that the combination of these resources was influential in how an individual coped with stress. Evidence that psychological capital can mediate the relationship suggests possibilities for future caregiver interventions aimed at increasing psychological capital and thereby reducing the detrimental effects of caregiving stressors.

The association between social support and caregiver wellbeing and perceived stress demonstrates the importance of giving caregivers opportunities to engage socially. As families are often separated by distance and are not always available to help or share the caregiving role, the primary caregiver may not have opportunity to take a break from their duties for any length of time [47-49].

In conclusion, this study demonstrates the merit of providing appropriate person-centred support services to people with dementia and their caregivers. The fact that psychological resources and social support appear to mediate the negative impact of caregiving on psychological health suggest that interventions which can boost these resources would benefit caregivers in the future, particularly if they support needs are met.

\section{References}

1. O'Connor C (2011) Caring for dementia carers: the role of general practitioners in Ireland. Ir J Med Sci 180(2): 327-332.

2. O'Shea (2007) Implementing policy for dementia care in Ireland. The time for action is now.
3. Pierce M, Cahill S, O’Shea E (2013) Planning dementia services: new estimates of current and future prevalence rates of dementia for Ireland. Ir J Psychol Med 30(1): 13-20.

4. Means R, Richards S, Smith R (2008) Community Care: Policy and Practice. ( $4^{\text {th }}$ edn), Basingstoke: Palgrave Macmillan. The British Journal of Social Work 38(7): 1454-1455.

5. Cahill S (2010) Developing a National Dementia Strategy for Ireland. International Journal of Geriatric Psychiatry 25: 912-916.

6. Schulz R, Martire LM (2004) Family caregiving of persons with dementia. Prevalence, health effects, and support strategies. Am J Geriatr Psychiatry 12(3): 240-249.

7. Allen AP, Curran E, Duggan A, Cryan, J F, Ní Chorcoráin, et al. (2017) A systematic review of the psychobiological burden of informal caregiving for care recipients with dementia: Focus on cognitive and biological markers of chronic stress. Neurosci Biobehav Rev 73: 123164.

8. Fonareva I, Oken BS (2014) Physiological and functional consequences of caregiving for relatives with dementia. Int Psychogeriatr 26(5): 725747.

9. Eska K, Graessel E, Donath C, Schwarzkopf L, Lauterberg J (2013) Predictors of institutionalization of dementia care recipients in mild and moderate stages: A 4-year prospective analysis. Dement Geriatr Cogn Dis Extra 3(1): 426-445.

10. Gaugler JE, Kane RL, Kane RA, Newcomer R (2005) Unmet care needs and key outcomes in dementia. J Am Geriatr Soc (12): 2098-2105.

11. Donnelly NA, Hickey A, Burns A, Murphy P, Doyle F (2015) Systematic review and meta-analysis of the impact of carer stress on subsequent institutionalisation of community-dwelling older people. PloS one 10(6): e0128213.

12.Schölzel-Dorenbos CJM, Meeuwsen EJ, Olde Rikkert MGM (2010) Integrating unmet needs into dementia health-related quality of life research and care: Introduction of the Hierarchy Model of Needs in Dementia. Aging Ment Health 14(1): 113-119.

13. Hughes TB, Black BS, Albert M, Gitlin LN, Johnson DM, et al. (2014) Correlates of objective and subjective measures of caregiver burden among dementia caregivers: influence of unmet care recipient and caregiver dementia-related care needs. Int Psychogeriatr 26(11): 1875-1883.

14. Li H (2012) Unmet service needs: A comparison between dementia and non-dementia caregivers. Home Health Care Serv Q 31(1): 41-59.

15. Richardson TJ, Lee SL, Berg-Weger M, Grossberg GT (2013) Caregiver health: Health of caregivers of Alzheimer's and other dementia care recipients. Health Rep 15(7): 367.

16. Raivio M, Eloniemi-Sulkava U, Laakkonen MJ, Saarenheimo M, Pietilä M, et al. (2007) How do officially organised services meet the needs of elderly caregivers and their spouses with Alzheimer's disease? Am J Alzheimers Dis Other Demen 22(5): 360-368.

17. Novais T, Dauphinot V, Krolak-Salmon P, Mouchoux C (2017) How to explore the needs of informal caregivers of individuals with cognitive impairment in Alzheimer's disease or related diseases? A systematic review of quantitative and qualitative studies. BMC Geriatr 17(1): 86.

18. Hobfoll SE (2002) Social and psychological resources and adaptation. Review of General Psychology 6(4): 307-324.

19. Han JW, Jeong H, Park JY, Kim TH, Lee DY (2014) Effects of social supports on burden in caregivers of people with dementia. Int Psychogeriatr 26(10): 1639-1648.

20. Clay OJ, Roth DL, Wadley VG, Haley WE (2008) Changes in social support and their impact on psychosocial outcome over a 5-year period for African-American and White dementia caregiver. Int J Geriatr Psychiatry 23(8): 857-862. 
21. Cherry MG, Salmon P, Dickson JM, Powell D, Sikdar S, et al. (2013) Factors influencing the resilience of carers of individuals with dementia. Reviews in Clinical Gerontology 23(4): 251-266.

22. Harmell AL, Chattillion EA, Roepke SK, Mausbach BT (2011) A review on the psychobiology of dementia caregiving: A focus on resilience factors. Curr Psychiatry Rep 13(3): 219-224.

23. Nogales-González C, Romero-Moreno R, Losada A, Márquez-González M, Zarit SH (2015) Moderating effect of self-efficacy on the relation between behaviour problems in persons with dementia and the distress they cause in caregivers. Aging Ment Health 19(11): 10221030.

24. Zhang S, Gui Q Edwards H, Yates P, Li C (2014) Self-efficacy moderation and mediation roles on BPSD and social support influences on subjective caregiver burden in Chinese spouse caregivers of dementia care recipients. International Psychogeriatrics 26: 1465-1473.

25. O'Rourke N, Kupferschmidt AL, Claxton A, Smith JZ, Chappell N, et al. (2010) Psychological resilience predicts depressive symptoms among spouses of persons with Alzheimer disease over time. Aging Ment Health 14(8): 984-993.

26. Joling KJ, Windle G, Dröes RM, Huisman M, Hertogh CMPM, et al. (2015) What are the essential features of resilience for informal caregivers of people living with dementia? A Delphi consensus examination. Aging Ment Health 21(5): 509-517.

27. Gallagher MW, Lopez SJ (2009) Positive expectancies and mental health: Identifying the unique contributions of hope and optimism. The Journal of Positive Psychology 4(6): 548-556.

28. Carver CS, Scheier MF (2014) Dispositional optimism. Trends Cogn Sci 18(6): 293-299.

29. Rand KL (2009) Hope and optimism: Latent structures and influences on grade expectancy and academic performance. J Pers 77(1): 231260 .

30. Valle MF, Huebner ES, Suldo SM (2006) An analysis of hope as a psychological strength. Journal of School Psychology 44(5): 393-406.

31. Luthans F, Avolio BJ, Avey JB, Norman SM, (2007) Positive psychological capital: Measurement and relationship with performance and satisfaction. Personnel Psychology 60(3): 541-572.

32. Avey JB, Luthans F, Jensen SM (2009) Psychological capital: a positive resource for combating employee stress and turnover. Human Resource Management 48(5): 677-693.

33. Avey JB, Luthans F, Smith RM, Palmer NF (2010) Impact of positive psychological capital on employee well-being over time. J Occup Health Psychol 15(1): 17-28.

34. Brickman AM, Riba A, Bell K, Marder K, Albert M, et al. (2002) Longitudinal assessment of patient dependence in Alzheimer disease. JAMA Neurology 59(8): 1304-1308.
35. Kelly M, Moran M (2010) Forget Me Not: A study of public health nurses and informal carers of people with dementia and Alzheimer's in Co. Galway.

36. Wyrwich KW, Auguste P, Buchanan J, Rudell K, Lacey L, et al. (2014) Psychometric properties of the dependence scale in large randomised clinical trials of care recipients with mild and moderate Alzheimer's disease. Am J Alzheimers Dis Other Demen. 29(7): 620-629.

37. Cohen S, Kamarck T, Marmelstein R (1983) A global measure of perceived stress. J Health Soc Behav 24(4): 385-396

38. Zimet GD, Dahlem NW, Zimet SG, Farley, GK (1988) The Multidimensional Scale of Perceived Social Support. Journal of Personality Assessment 52(1): 30-41.

39. Tennant R, Hiller L, Fishwick R, Platt S, Joseph S, et al. (2007) The Warwick-Edinburgh Mental Well-Being Scale (WEMWBS): Development and UK validation. Health Qual Life Outcomes 5: 63.

40. Sörensen S, Duberstein P, Gill D, Pinquart M (2006) Dementia care: Mental Health effects, intervention strategies, and clinical implications. The Lancet Neurology 5(11): 961-973.

41. Shields M (2004) Stress, health and the benefit of social support. Health Rep 15(1): 9-38.

42. Thoits P A (2011) Mechanisms linking social ties and support to physical and mental health. J Health Soc Behav 52(2): 145-161.

43. Wang X, Cai L, Qian J, Peng J (2014) Social support moderates stress effects on depression. Int J Ment Health Syst 8(1): 41.

44. Donnellan WJ, Bennett KM, Soulsby LK (2016) Family close but friends closer: exploring social support and resilience in older spousal dementia carers Aging Ment Health 21(11): 1222-1228.

45. Au A, Lai MK, Lau KM, Pan PC, Lam L, et al. (2009) Social support and well-being in dementia family caregivers: The mediating role of selfefficacy. Aging Ment Health 13(5): 761-768.

46. Rabenu E, Yaniv E (2017) Psychological resources and strategies to cope with stress at work. International journal of Psychological Research 10(2): 8-15.

47. Luthans F, Norman SM, Avolio BJ, Avey JB (2008) The mediating role of psychological capital in the supportive organizational climateemployee performance relationship. Journal of Organisational Behaviour 29(2): 219-238.

48. O'Shea E, Timmons S, O'Shea E, Fox S, Irving K (2017) Respite in dementia: An evolutionary concept analysis. Dementia.

49. Pickard L (2008) Informal Care for Older People Provided by Their Adult Children: Projections of Supply and Demand to 2041 in England, Report to the Strategy Unit and Department of Health Canterbury: Personal Social Services Research Unit.

\begin{tabular}{l} 
Your next submission with Juniper Publishers \\
will reach you the below assets \\
- Quality Editorial service \\
- Swift Peer Review \\
- Reprints availability \\
- E-prints Service \\
- Manuscript Podcast for convenient understanding \\
- Global attainment for your research \\
- Manuscript accessibility in different formats \\
( Pdf, E-pub, Full Text, Audio) \\
- Unceasing customer service \\
Track the below URL for one-step submission \\
https://juniperpublishers.com/online-submission.php \\
\hline
\end{tabular}

